\title{
ClAVES ARISTOTÉLICAS DE LA DEFENSA DE LA COETERNIDAD DEL MUNDO EN EL DE AETERNITARE MUNDI CONTRA MURMURANTES DE TOMÁS DE AQUINO
}

\author{
ARISTOTELIAN KEYS OF THE WORLD'S COETERNITY DEFENSE \\ IN THE DE AETERNITATE MUNDI CONTRA MURMURANTES \\ OF THOMAS AQUINAS \\ Ana María C. Minecan
}

\begin{abstract}
RESUMEN
El presente artículo analiza el influjo de los tratados aristotélicos Física y Acerca del cielo en la redacción de uno de los más controvertidos opúsculos atribuidos a Tomás de Aquino, el De aeternitate mundi contra murmurantes. Se estudia, comparativamente, el rechazo de Aristóteles de un comienzo temporal para el mundo físico y se analiza el empleo y la reformulación por parte del Aquinate de las categorías aristotélicas para ofrecer una nueva reinterpretación de la creación en la cual se defiende, en contra de lo prohibido en las condenas del siglo XIII, la coeternidad del mundo creado y la divinidad.
\end{abstract}

PALABRAS CLAVE: Tomás de Aquino, Aristóteles, eternidad, coeternidad, creación, física medieval.

\begin{abstract}
This article analyzes the influence of the Aristotelian treatises Physics and On the Heavens on the writting of one of the most controversial opuscule attributed to Thomas Aquinas, De aeternitate mundi contra murmurantes. It is studied comparatively the rejection of Aristotle of a temporal beginning for the physical world and the employment and reformulation by Aquinas of the Aristotelian categories to offer a new reinterpretation of creation in which he defends, against the condemnations of the thirteenth century, the coeternity of the created world and divinity.
\end{abstract}

KEYWORDS: Thomas Aquinas, Aristotle, eternity, coeternity, creation, medieval physics. 
Entre los distintos desafíos que los llamados Libros Naturales de Aristóteles presentaron al dogma cristiano, a su llegada a la Universidad de Paris del siglo XIII (Van Steenberghen, 1972, p. 28), uno de los más controvertidos fue su sólida defensa de la eternidad del mundo. Esta tesis, completamente contraria a los contenidos fundamentales de la cosmovisión cristiana se convirtió, desde los primeros contactos con los nuevos textos, en una de las principales dianas de los ataques de los pensadores tardomedievales. (Ruething, 1973, p. 53)

Es posible hallar referencias a los tratados aristotélicos dedicados a cuestiones físicas en las condenas más tempranas promulgadas en el ámbito universitario, como la del arzobispo de la provincia de Sens y el obispo de Paris fechada en $1210^{1}$ o la prescrita por Roberto de Courçon en $1215^{2}$.

1 "Decreta magistri Petri Corbolio Senonensis archiepiscopi, Parisienis eposcopi, atque aliorum episcopoum Parisiis congregatorum super haereticis comburendis et super libris Aristotelis aliorumque. Corpus magistri Amaurici extrahatur a cimenterio et projiciatur in terram non benedictam, et idem excommunicetur per omnes ecclesias totius provincie. Bernardus, Cuilelmus de Arria aurifaber, Stephanus presbyter de Veteri Corbolio, Stephanus presbyter de Cella, Johannes presbyter de Occines, magister Willelmus Pietaviensis, Dudo sacerdos, Dominucus de Triangulo, Odo et Elinans clerici de S. Clodoaldo, isti degradentur penitus seculari curie relinquendi. Urricus presbyter de Lauriaco et Petrus de S. Clodoaldo, modo monachus S. Dionysii, Guarinus presbyter de Corbolio, Stephanus clericus degradentur perpetuo carceri mancipando. Quaternuli magistri David de Dinant infra natale episcopo Parisiense afferantur et combuantur, nec libri Aristotelis de naturali philosopia nec commenta legantur Parisius publice vel secreto, et hoc sub penae xcomuicationis inhibemus. Apud quem invenientur quaternuli magistri David a natali Domini in antea pro heretico habebitur." Denifle, H. et Châtelain, E., Chartularium Universitatis Parisiensis, vol.I, Delalain, Paris, 1889. I, nº 11,p. 70.

2 "Robertus cardinalis legatus praescribit modum legendi in artibus et in teologia indicat quos libros magistri artium non debeant legere, ordinat disciplinam scholarium et generaliter statum Universitatis. R. servus crucis Christi divina miseratione tituli Sancti Stephani in Celio Monte presbyter cardinalis apostolice sedis legatus, univerisis magistris et scolaribus Parisienssibus salutem in Domino Sempiternam. Noverint universi, quod cum domini pape speciale habuissemus mandatum, ut statui Parisiensium scolarium in melius reformando impenderemus operam efficacem, nos de bonorum virorum consilio scolarum tranquilitati volentes in posterum providere, ordinavimus et statuimus in hunc modum: Nullus legat Parisius de artibus citra vicesimum primum etatis sue annum, et quod sex annis audierit de artibus ad minus antequam ad legendum accedat, et qued protestentur se lecturum duobus annis ad minis, nisi rationabilis causa intercenerit, quema publice vel coram examinatoribus debebit probare, et quod non si tespersus aliquea infamia, et quod cum legere disposuerit, examinetur quilibet secundum formam, que continetur in scripto domini P. Parisienses episcopi, ubi continetur pax confirmata inter cancellarium et scolares a judicibus delegatis a domino papa, silicet ab episcopo et decano Trescensibus, et a P. eposcipo et J. cancellario Parisien. approbata et confirmata. El quod 
En la segunda mitad del siglo XIII, el reconocimiento de la eternidad del mundo como una de las tesis más peligrosas para la ortodoxia era generalizado entre los teólogos y las autoridades eclesiásticas (Lloyd, 2007, p. 224). Su defensa aparece claramente condenada en las trece proposiciones prohibidas en $1270^{3}$, preludio del famoso Syllabus de 1277 en el cual se condena la eternidad del mundo, desde distintos puntos de vista, en 47 de las 219 condenas ${ }^{4}$.

El proceso de contagio del pensamiento aristotélico fue, sin embargo, imparable, llegando a figurar el conjunto recuperado del corpus aristotélico como lectura obligatoria en la Facultad de Artes de París, tal y como lo demuestra el reglamento publicado el 19 de marzo de $1255^{5}$. A pesar de las prohibiciones, la filosofía aris-

legant libros Aristotelis de dialectica tam de Viteri quam de nova in scolis oridinarie et non ad cursum. Legant enima in scolis ordinarie duos Priscianos vel alterum ad minus. Non legant in festivis diebus nisi pilosophos et rhetoricas, et quadruvialia, et, barbarismum, et ethicam, si placet, et quartum topichorum. Non legantur libri Aristotelis de methafisica et de naturali philosophia, nec summe de eisdem, aut de doctrina magistri David de Dinant, aut Almarici heretici, aut Mauricius hyspani." Ib. I, p.78, n. 20.

${ }^{3}$ Isti sunt errores condempnati et excommunicati cum onmibus, qui eos docuerint scienter vel asseruerint, a domino Stephano, Parisiensi episcopo, anno Domini MCCLXX, die mercurii post festum beati Nicholai hyemalis. Primus articulus est : 1.Quod intellectus omnium hominum est unus et idem numero. 2. Quod ista est falsa vel impropria : Homo intelligit. 3. Quod voluntas hominis ex necessitate vult vel eligit. 4. Quod omnia, que hic in inferioribus aguntur, subsunt necessitati corporum celestium. 5. Quod mundus est eternus. 6. Quod nunquam fuit primus homo. 7. Quod anima, que est forma hominis secundum quod homo, corrumpitur corrupto corpore. 8. Quod anima post mortem separata non patitur ab igne corporeo. 9. Quod liberum arbitrium est potentia passiva, non activa : et quod necessitate movetur ab appetibili. 10. Quod Deus non cognoscit singularia. 11. Quod Deus non cognoscit alia a se. 12. Quod humani actus non reguntur providentia Dei. 13. Quod Deus non potest dare immortalitatem vel incorrupcionem rei corruptibili vel mortali." Ib. I, pp. 486-487 n. 432.

${ }^{4} I b . \mathrm{I}, \mathrm{n}^{\mathrm{o}} 473$.

5 "Anno Domini MCCL quarto.Noverint universi, quod nos omnes et singuli magistri artium de communi assensu nostro, nullo contradicente, ... statuimus et ordinavimus, quod omnes et singuli magistri nostrae facultatis imposterum libros... absolvere...teneantur: Veterem logicam, videlicet librum Porphyrii, Praedicamentorum, Perihermenias, Divisonum etTopicorum Boethii, excepto quarto...Priscanum minorem et maiorem, Topica et Elencos, Priora et Posteriora... Ethicas quantum ad IV libros... Tres parvos libros, videlicet Sex principia, Barbarismum, Pricanum De accentu...Physicam Aristotelis, Metaphisicam et librum De animalibus... librum Caeli et mundi, librum primum Meteorum cum quarto... librum De anima... librum De generatione... librum De causis30... librum De sensu et sensato... librum De somno et vigilia... librum De plantis... librum De memoria et reminiscencia... librum De differentia spiritus et animae... librum De morte et de vita.” Ib. I, p. 228, nº 201. 
totélica, a mitades del siglo XIII, había formado a las generaciones de maestros y doctores en teología que protagonizaron la etapa final de recepción y asimilación temprana, hasta la gran condena de 1277 (Thijssen, 1997).

En la vorágine de este siglo de traducciones, comentarios y condenas, destaca la figura del dominico Tomás de Aquino que habría de pasar a la historia del pensamiento occidental como el principal artífice de la "cristianización" de Aristóteles (Torrell, 2005, p.301). Si bien sus obras más conocidas están repletas de páginas dedicadas a la refutación de esta tesis aristotélica, destaca entre sus textos un breve y original opúsculo de gran interés para la investigación de la asimilación de la física en la Baja Edad Media. El De aeternitate mundi, conocido posteriormente como De aeternitate mundi contra murmutantes constituye un documento excepcional desde varios puntos de vista (Wippel, 1991).

En primer lugar, resulta interesante por su datación, situada en torno a 1270, momento en el que se hicieron públicas las trece condenas formales a la filosofía de Aristóteles en las cuales, como hemos visto más arriba, aparece claramente prohibida la tesis de la eternidad del mundo.

Igual de importante es su título, del cual es posible deducir que Tomás de Aquino se sintió obligado a posicionarse ante las controversias frente a esos misteriosos murmurantes que bien podrían ser los aristotélicos radicales de la Universidad de París como los maestros Siger de Brabante o Boecio de Dacia o bien los comentaristas árabes de Aristóteles, como Averroes, cuyos textos eran leídos con profusión en las aulas del momento (Carroll, 2013).

Sin embargo, lo más excepcional de este escrito no puede deducirse de todo lo dicho hasta ahora pues, a primera vista, el opúsculo podría parecer un simple tratado más de los muchísimos redactados en la época con el fin de rechazar tajantemente la eternidad y defender la creatio ex nibilo por parte de Dios. Lejos de esto, la sorpresa del lector acostumbrado a estos enfoques más habituales, llega al comprobar que lo que el Aquinate analiza en el De aeternitate mundi es la posibilidad misma de compatibilizar la idea aristotélica de eternidad con el concepto cristiano de creación. El objetivo del breve tratado no es, por tanto, otro que el de comprobar si es posible sostener la existencia de algo creado pero eterno.

Este raro y original enfoque nos permite comprender el calado que el influjo aristotélico tuvo sobre el pensamiento del Aquinate. En lugar de optar por la solución más sencilla, que le habría llevado a rechazar por la fe, sin más, todo lo sostenido por Aristóteles, Tomás de Aquino se esforzó por conservar todo lo que del pensamiento del Estagirita le resultó racionalmente concluyente. 


\section{EL MUNDO TUVO UN COMIENZO DE DURACIÓN}

El primer posicionamiento de Tomás de Aquino en la obra ${ }^{6}$ es tajante y, al mismo tiempo, evasivo frente a los desafíos de la Física y el Acerca del Cielo pues establece, sin discusión, que el mundo tuvo comienzo de duración ${ }^{7}$. Este postulado inicial, según el cual se afirma la efectiva existencia de un punto inicial en el desarrollo temporal del cosmos, no es sometido a un examen - como es habitual en el Aquinate-, desde el punto de vista de la razón sino que se impone como dogma inapelable.

Sin embargo, la ausencia en este opúsculo de un desarrollo del problema por parte del comentador dominico, puede generar la falsa impresión de que la afirmación de la eternidad del mundo es igualmente abrupta en los tratados físicos aristotélicos. Nada más lejos de la realidad, pues la cuestión del comienzo temporal del mundo recibe un análisis exhaustivo por parte del Estagirita del cual se sirvió el propio Tomás de Aquino para redefinir su propio concepto de creación, como veremos más adelante.

\section{LA ETERNIDAD DEL MUNDO EN LA FILOSOFÍA DE ARISTÓTELES}

La estrategia seguida por Aristóteles para defender la eternidad del mundo consistió en demostrar su evidencia a través del análisis de los elementos constitutivos y reguladores característicos de lo natural, entre los cuales, el punto clave lo constituye el movimiento.

Partiendo de la definición de los principios, las causas, los elementos, el tiempo, la materia y la forma, el Estagirita dibujó la necesaria eternidad y, con ello, la absoluta imposibilidad de sostener un comienzo — al igual que un final— en lo que se refiere a la duración temporal del mundo (Lang, 1992, p. 35-40).

En los primeros capítulos del tratado de la Física, Aristóteles analizó los rasgos fundamentales de los principios que gobiernan lo natural. Frente a la posición de

\footnotetext{
${ }^{6}$ Me refiero a la primera frase del texto en la cual se establece tanto el axioma de partida "el mundo tuvo comienzo de duración" como el problema que se va a tratar a lo largo del resto de la obra: “(...) ha surgido la duda de si pudiera haber existido siempre." (Tomás de Aquino, 2002, p. 16)

7 Se postula, siguiendo el dogma cristiano, que el mundo comenzó en un momento cronológico determinado anterior al cual no había tiempo. Desde el punto de vista aristotélico, si no existía el tiempo tampoco había movimiento. Aplicando a esta situación las coordenadas de la física del Estagirita se sigue que con anterioridad al mundo lo que existía era un estado de reposo atemporal.
} 
Meliso, según la cual todo lo que ha llegado a ser tuvo un comienzo, se declara abiertamente que tal afirmación es absurda, al igual que toda posición que postule un comienzo del tiempo, de la generación absoluta o de la generación de las cualidades (Aristóteles, 2008a, I 3, 186a10-16). Las razones últimas de esta radical oposición al comienzo y destrucción temporal del universo se hallan repartidas por todo el corpus aristotélico y su defensa tiene consecuencias no sólo a nivel físico sino también metafísico, ontológico y epistemológico.

El Estagirita estableció como características fundamentales de los primeros principios el hecho de que no puedan provenir de otras cosas porque son primeros, ni provenir unos de otros porque son contrarios, sino que de ellos provengan todas las cosas (Aristóteles, 2008a, I 5,188a26-30). Estos principios, a su vez, no pueden actuar unos sobre otros, no pueden alterarse ${ }^{8}$ ni son, en sí mismos, sustancia de ninguna cosa, sino que bajo ellos existe una naturaleza distinta. Esta tercera naturaleza, operada por los principios eternos, debe ser, a su vez, un sustrato pasivo igualmente eterno, dado que la acción de los primeros es constante y necesaria (Aristóteles, 2008a, I, 1-5.) en virtud de su propia esencia. La materia, por tanto, entendida como constitutivo primero y no accidental de lo que llega a ser, es considerada potencia pasiva en sí misma que no se destruye sino que necesariamente es eterna (Aristóteles, 2008a, I 9, 192a25-30).

En el tratado de la Física, a la existencia eterna de los constituyentes primeros que componen y regulan el orden natural, se une la necesaria eternidad del dinamismo que anima y permite los cambios y mutaciones albergadas por el cosmos. La existencia del movimiento es algo del todo evidente para Aristóteles y ha de ser admitida, en su opinión, sin necesidad de demostración pues no hay alternativa explicativa alguna si se quiere hablar de generación y corrupción, ya que sin movimiento tanto estos dos tipos de cambios como el aumento, la alteración y el desplazamiento no podrían existir (Coope, 2015).

De la propia conceptualización aristotélica del movimiento se sigue, además, que para que haya movimiento es necesaria la existencia de sujetos capaces de moverse. Así, mientras haya movimiento, existirán algunos entes móviles que serán

\footnotetext{
8 Todo principio ha de ser principio de algo distinto, de algo otro porque los principios no pueden actuar unos sobre otros. La razón de esta imposibilidad es clara. Si un principio tuviera la suficiente fuerza de modificar en algo a su contrario debilitaría la capacidad de éste limitando su capacidad de operar. Si dicha fuerza fuera lo suficientemente grande podría incluso anular a su opuesto. La consecuencia sería el cese inmediato de todo tipo de cambio y movimiento. (Aristóteles, 2008, I, 6.)
} 
finitos si el movimiento tuvo un comienzo o eternos si éste existe siempre. Pero si cada una ${ }^{9}$ de las cosas móviles hubiese sido generada, entonces con anterioridad a este movimiento tendría que haber habido otro cambio o movimiento, aquel por el cual fue generado lo que puede ser movido o mover (Von Leyden, 1964).

Suponer, en cambio, con anterioridad al movimiento la existencia eterna de móviles y motores constituye un absurdo. Esto es, si se propone que entre las cosas móviles y motrices, en algún tiempo, una sea la que primero mueva y otra la que primero es movida y que, en otro tiempo anterior, no hay sino reposo, entonces resultará necesario remontarse al tiempo anterior a dicho reposo ${ }^{10}$ y postular un cambio previo ${ }^{11}$. Si esto es así, dicho reposo supuestamente inicial ha de tener una causa por la cual se detuviera el movimiento anterior. Habría que sostener, entonces, la necesidad de un cambio con anterioridad al primer cambio. (Aristóteles, 2008a, VIII 1, 251a17-27.)

Por otro lado, según Aristóteles, si una generación absoluta hubiese sido alguna vez generada en algún tiempo ${ }^{12}$, también lo que la generó tendría que haber sido generado, de suerte que todavía no llegaríamos a algo que fuese generado absolutamente, sino a algo generado en proceso de ser generado. De este modo, jamás habría un tiempo en el que lo generado hubiese sido generado. No obstante, como en una serie infinita no hay un primer término, no habría entonces un primer generado ni tampoco otro generado que le siga inmediatamente (Wedin, 2013). Por consiguiente, es preciso que haya siempre movimiento y que éste no se interrumpa jamás. Si ello es así, tiene que haber también algo eterno que mueva primero y esto eterno, sea uno o múltiple, debe ser necesariamente inmóvil para evitar un regreso al infinito no explicativo.

La conclusión final de Aristóteles rechaza tanto lo inmóvil destructible como lo móvil y eterno, para establecer como causa última del movimiento incesante

\footnotetext{
9 Con ello Aristóteles no establece que todas y cada una de las cosas móviles del universo hayan de ser eternas sino que, al menos, debe haber, entre todas ellas algunas que lo sean.

10 En el sistema aristotélico el reposo no es más que la privación del movimiento. (Aristóteles, 2008. III, 1-4.)

11 De la misma manera razona Aristóteles acerca sobre la destrucción del movimiento, pues al igual que en la generación del mundo se muestra necesaria la existencia de un cambio anterior al primer cambio en el caso de la destrucción habrá un cambio posterior al último cambio.

12 La generación y la destrucción, que son características propias de los compuestos sensibles, son cambios esencialmente temporales: "porque las cosas se generan y se destruyen y aumentan en el tiempo, y también se alteran y se desplazan en el tiempo." (Aristóteles, 2008, IV, 14, 223a3031. No puede haber, dentro del sistema aristotélico algo así como una generación atemporal.
} 
y continuo que se comunica mecánicamente a través de los sucesivos motores y mantiene el dinamismo del cosmos, al primer motor inmóvil (Aristóteles, 2008a, VIII 6, 260a1-10). Pero si hay un primer motor inmóvil y eterno, lo que primero es movido por dicho motor también deberá ser eterno puesto que, de lo contrario, se anularían todos los procesos generación y destrucción (Torrijos-Castrillejo, 2013).

Consecuentemente, si se acepta la eternidad del movimiento, el tiempo, que no es para Aristóteles más que el número del movimiento, (Bowin, 2009) también será eterno (Aristóteles, 2008a, IV 13, 222a31.) En este sentido, puesto que el ahora es un fin y un comienzo del tiempo, pero no del mismo tiempo, sino fin del que ha pasado y comienzo del que ha de venir, se sigue que el tiempo está siempre en un comienzo y un fin, razón por la cual se concluye en la Física que el tiempo no se extinguirá porque siempre está comenzando.(Aristóteles, 2008a, IV 13,222b1-6)

En definitiva, si el tiempo y el movimiento son eternos y si toda generación y destrucción se da en el tiempo, existiendo además de modo necesario motores eternos, principios y un sustrato subyacente, resulta evidente la dificultad de encajar, en el sistema aristotélico, las ideas de creación o generación absoluta.

\section{REFORMULACIÓN DE LA NOCIÓN DE CREACIÓN}

La clave necesaria para escapar a las demoledoras conclusiones aristotélicas no fue otra, para el Aquinate, que la reformulación de la noción de creación a partir de vectores neoplatónicos, en combinación con el reconocimiento de la nueva causa omnipotente y voluntaria no considerada por el griego. Si Aristóteles había establecido que toda generación implica un cambio desde algo anterior hacia algo posterior y que, por consiguiente, se da necesariamente en el tiempo, entonces la creación del mundo por parte de Dios deberá ser de una naturaleza tal que evite ambas prisiones.

Una de las características del tiempo y el movimiento aristotélicos es su desarrollo sucesivo susceptible de ser cuantificado numéricamente en una serie ordenada. De modo general, pueden identificarse al menos tres elementos básicos, en virtud de los cuales se realizan las determinaciones dinámicas y temporales, derivados por Aristóteles de la analogía con la magnitud: el antes/desde, el intermedio ${ }^{13}$ y el después/hacia lo que. Si en toda magnitud existe un antes y un después, en el

13 Este intermedio es el ahora que según Aristóteles es la continuidad del tiempo puesto que enlaza el pasado con el futuro y, al mismo tiempo la división potencial y límite del tiempo ya que marca el comienzo y final de los distintos ahoras. (Aristóteles, 2008, IV, 13.) 
movimiento también debe haberlo y si el tiempo, a su vez, sigue siempre al movimiento deberá haber también un antes y un después en él.

De ello, concluye Aristóteles que la constatación del tiempo (Coope, 2005) se realiza cuando se efectúa la intelección de la existencia sucesiva de dos extremos diferentes entre sí, y a su vez, distintos de un tercero, el intermedio, también diferente y situado entre ellos. A ello hay que añadir que tanto el tiempo como el movimiento no son, para Aristóteles, entidades susceptibles de ser consideradas como ontológicamente independientes de las sustancias.

Es decir, el tiempo se conoce por el movimiento y el movimiento, a su vez, es conocido por la cosa que mueve o es movida. Sólo de la cosa se puede decir que es un "esto", pero no así del movimiento ni del tiempo que no son entidad. Lo que el Estagirita establece es una implicación necesaria (Aristóteles, 2008a, IV, 12.) según la cual para lo que "es en el tiempo",cuando existe, tiene que haber necesariamente tiempo y para lo que "es en el movimiento", cuando existe, tiene que haber necesariamente un movimiento.

La generación obrada por el Ser supremo, por tanto, si quiere escapar al movimiento y al tiempo debe acontecer de un modo distinto. La solución propuesta por el Aquinate fue la de concebirla como emanación simultánea o instantánea (Tomás de Aquino, 2002, p. 25). La noción de emanación intenta evitar el sustrato subyacente requerido por todo cambio y movimiento mientras que la noción simultaneidad pretende superar los condicionantes del tiempo cronológico ${ }^{14}$.

Esta nueva reformulación se muestra altamente eficaz para salvar las dificultades aristotélicas, pues si se acepta que la producción de todo el ser por la primera causa no es movimiento, entonces no puede aducirse en contra que antes del primer cambio sea necesario otro cambio. Esto sólo se seguiría si los motores y los móviles fueran producidos por algún agente particular que obrara supuesto algún sujeto que cambiara del no ser al ser, o de la privación a al forma, según lo plantea Aristóteles.

De la misma forma, gracias a la nueva generación atemporal e inmóvil, se solventa el problema planteado por el Estagirita según el cual si, preexistiendo los motores y los móviles, el movimiento tiene un comienzo es necesario que antes

\footnotetext{
${ }^{14}$ En términos aristotélicos, los cambios entre contradictorios, en la medida en que sólo pueden efectuarse accidentalmente y no de modo absoluto requieren un sustrato subyacente. A su vez, la sucesión cronológica obliga a hablar de un tiempo anterior y posterior a la generación y la destrucción.
} 
los motores o los móviles no estuviesen en la disposición que están cuando hay movimiento, razón por la cual surge la necesidad de que al primer cambio le preceda algún otro cambio.

La respuesta a esta objeción es sencilla, según el Aquinate, pues la razón por la que los móviles no estaban ciertamente en la disposición en la que están ahora es el hecho de que antes no existían y, por ello, no podían moverse. Por tanto, no adquieren el ser por cambio o movimiento sino por emanación del primer principio de las cosas. De ello se sigue, según el Doctor Ängélico que no debe entenderse que hubiera un tiempo infinito precedente en el cual la divinidad permaneciera pasiva y que posteriormente comenzara su labor creadora en un tiempo determinado, sino que Dios produjo simultáneamente el tiempo y las cosas que con anterioridad no existían en sentido absoluto.

Finalmente, ante la objeción de Aristóteles de que un principio del tiempo implicaría un tiempo antes del tiempo, el Aquinate desarrolló una nueva definición de eternidad con la que pretendió superar la manera aristotélica de concebirla como sucesión continua e ilimitada de aboras discretos.

Según Tomás de Aquino, existe un tipo de duración anterior al tiempo carente de extensión anterior y posterior. Ésta es la eternidad de Dios que se diferencia precisamente por ser toda simultánea. Apelando a esta nueva definición de eternidad el Aquinate pudo mantener que no se afirma ninguna duración sucesiva anterior al mundo en la concepción cristiana de la creación y escapar, con ello, al reto aristotélico.

\section{EL MUNDO PUEDE SER ETERNO}

Una vez establecidas las dos condiciones de partida según las cuales la duración del mundo tuvo un inicio y la creación por parte de Dios no supone un sustrato, un movimiento, ni un tiempo anterior, el Aquinate se dispuso a analizar la posibilidad de que el mundo haya podido existir siempre mediante la refutación de las distintas alternativas que podrían objetarse a ello. Según el Aquinate, al problema tratado pueden oponérsele tres cuestiones iniciales a las que hay que dar respuesta:

i. La posibilidad de que exista algo eterno no creado por Dios.

ii. La posibilidad de que Dios no pueda crear algo eterno.

iii. La posibilidad de que pueda ser creado por Dios algo eterno pero que no haya podido ser hecho por otras razones. (Tomás de Aquino, 2002, p.17) 
En primer lugar, se rechaza toda posibilidad de que algo fuera de Dios pudiera existir siempre. Con fuera el Aquinate se refiere aquí a algo cuya existencia no pueda ser remitida a la acción divina. ${ }^{15}$

Tal suposición, sin embargo, error abhominabilis est para la fe pues, frente a otros aspectos más o menos problemáticos de la física aristotélica que podían recibir interpretaciones teológicas diversas, la creación de todo lo existente por parte de Dios no constituía un ámbito flexible y poco determinado, abierto al debate universitario, sino que su afirmación estaba contenida de forma explícita en las Escrituras (Biblia, Génesis 2: 1-4).

Junto al propio texto bíblico, la exégesis cristiana, desde los tiempos más tempranos, ofreció numerosos ejemplos de la defensa de la creación absoluta tal y como ésta es expuesta en el Génesis. Entre ellos, podemos destacar el De principiis de Orígenes donde se niega la existencia de una materia preexistente a partir de la cual Dios hubiera podido crear el universo (Orígenes, 2001, II, c.1-4) o el Adversus haereses de San Ireneo donde se define el mundo como creado por la voluntad libre de Dios (Irénée de Lyon, 1965, II, c. 1, 46). No debemos olvidarnos, además, de la famosa caracterización de San Agustin de la creación como ex nibilo sui et subiecti. Para el filósofo africano todo el cosmos en su totalidad había sido creado, sacado de la nada, por causa del Verbo, de tal forma que antes de que el mundo fuera hecho nada existía, excepto Dios eterno (Agustín de Hipona, 2005, XI, 4, 1.)

Ya en el siglo XIII, el Concilio Lateranense IV, celebrado en 1215, enunció solemnemente el famoso Decreto Firmiter al que Tomás de Aquino dedicó un extenso comentario, en el cual se establece de forma clara el inicio temporal del mundo:

Pater generans filius nascens et spiritus sanctus procedens consubstantiales et coaequales coomnipotentes et coaeterni unum universorum principium creator omnium invisibilium et visibilium spiritualium et corporalium qui sua omnipotenti virtute simul ab initio temporis utramque de nihilo condidit creaturam spiritualem et corporalem angelicam videlicet et mundanam ac deinde humanam quasi communem ex spiritu et corpore constitutam. (Mansi, 22,932.)

Según el dogma, no sólo es imposible que exista algo eterno no creado por Dios sino que, sea cual sea la cualidad temporal de su existir, el ser de todo lo que

\footnotetext{
15 "Si enim intelligatur quod aliquid praeter Deum potuit Samper fuiste quasi possit esse aliquid, tamen ab eo non factum, error abhominabilis est, non solum in fide, sed etiam apud philosophos, qui confitentur et probant omne quod est quocumque modo esse non posse, nisi sit causatum ab o qui maxime et verissime esse habet. (Tomás de Aquino, 2002, p. 16)
} 
hay debe necesariamente su existencia a la divinidad, no pudiendo hablarse de ninguna manera de un "fuera" de Dios.

Por tanto, se establece como primera condición que el mundo — eterno o finito temporalmente-, ha de ser necesariamente causado. No obstante. la causación no impide, para el Doctor Angélico, seguir manteniendo abierta la posibilidad de una existencia eterna de la creación. Rechazar esta posibilidad implicaría la consiguiente asunción de una de estas dos posibilidades:

I. Dios no puede hacer algo que exista siempre.

II. Teniendo Dios el poder de hacer que algo exista siempre, ello no pudo ser hecho $^{16}$ :

a. Por desaparición de la potencia pasiva.

b. Por incompatibilidad de los conceptos. ${ }^{17}$

La primera posibilidad es rechazada inmediatamente en virtud de la infinita potentia Dei (Tomás de Aquino, 2002, p.17) por la cual el ser supremo pudo hacer algo que siempre existiera puesto que su capacidad y poder de obrar no puede verse coartada por ningún límite. Queda, en consecuencia, por analizar si es posible que sea hecho algo que haya existido siempre.

\section{DESAPARICIÓN DE LA POTENCIA PASIVA}

Para resolver la primera formulación de la segunda dificultad el Aquinate se apoyó en una consecuencia derivada del dogma para negar la eternidad de la potencia pasiva. Tomando como ejemplo el ángel, ser creado y eterno, que es forma pura y, por tanto, no sometida a la corrupción derivada de la indeterminación de la materia, Tomás señala que podría decirse que antes de que el ángel fuera hecho, "el ángel no puede ser hecho" porque no precede a su existencia potencia pasiva alguna. (Tomás de Aquino, 2002, p. 19)

Es decir, al ser el ángel forma inmaterial, se sigue que en ningún momento pudo estar dicha forma en potencia de aparecer ya que, al carecer de sustrato material, tal estado le es imposible por su propia esencia definitoria. Antes de que la

\footnotetext{
16 "Si autem dicatur hoc esse impossibile, vel hoc dicetur quia Deus non potuit facere aliquid quod semper fuerit, aut quia non potuit fieri, et si Deus posset facere." (Tomás de Aquino, 2002, p. 16)

17 "Si autem dicatur quod hoc non potest fieri, hoc non potest intelligi nisi duobus modis, vel duas causas veritatis habere: vel propter remotionem potentiae passivae, vel propter repugnantiam intellectuum.” (Tomás de Aquino, 2002, p. 16)
} 
forma del ángel sea creada por la divinidad puede decirse, ciertamente, que algo eterno como el ángel no puede ser hecho pues no le puede corresponder existencia potencial alguna. ${ }^{18}$

Entendiéndolo de este modo, según la fe es ciertamente verdadero sostener que algo creado no pueda existir siempre porque de lo contrario se afirmaría la coexistencia eterna con Dios de la potencia pasiva. Si tal posibilidad se aceptara de hecho, la divinidad ya no podría considerarse un creador absoluto sino que quedaría reducida a un mero demiurgo.

$\mathrm{Al}$ mismo tiempo, la existencia del ser postulado sería eterna tanto a parte ante, desde el punto de vista potencial, como a parte post, tras su creación o actualización. Sin embargo, según el Aquinate, el poder divino pudo hacer el ángel y hacer que fuera hecho porque, de hecho, lo hizo. Si esto es así, según la fe, es necesario negar que lo causado pueda existir siempre pues de lo contrario se caería en la afirmación de que la potencia pasiva existió siempre lo cual es herético pues, como hemos señalado antes, sólo a Dios se le puede atribuir tal cualidad. Pero si bien esto es cierto, para Tomás de Aquino, tampoco se sigue de ello que Dios no pueda hacer algo que sea siempre ente ${ }^{19}$. (Tomás de Aquino, 2002, p. 19)

\section{INCOMPATIBILIDAD CONCEPTUAL}

La segunda dificultad que se puede aducir, y de mayor calado para el estudio de la asimilación de la física aristotélica, hace referencia a la incompatibilidad de los conceptos ser hecho y ser eterno. Según el Aquinate, si la combinación de estos dos conceptos repugnara al intelecto ocurriría algo semejante a sostener que la afirmación y la negación sean verdaderas simultáneamente. ${ }^{20}$

18 "Primo modo posset dici, antequam Angelus sit factus, non potest Angelus fieri, quia non praeexistit ad eius esse aliqua potentia passiva, cum non sit factus ex materi a praeiacente; tamen Deus poterat facere Angelum, poterat etiam facere ut Angelus fieret, quia fecit, et factus est. Sic ergo intelligendo, simpliciter concedendum est secundum fidem quod non potest creatum semper esse: quia hoc ponere esset ponere potentiam passivam semper fuisse: quod haereticum est." (Tomás de Aquino, 2002, p. 18)

19 "Tamen ex hoc non sequitur quod Deus non possit facere ut fiat aliquid semper ens." (Tomás de Aquino, 2002, p. 18)

20 "Secundo modo dicitur propter repugnantiam intellectuum aliquid non posse fieri, sicut quod non potest fieri ut affirmatio et negatio sint simul vera; quamvis Deus hoc possit facere, ut quidam dicunt. Quidam vero dicunt, quod nec Deus hoc posset facere, quia hoc nihil est." (Tomás de Aquino, 2002, p. 18) 
Si bien algunos pensadores consideraron que esto entraba dentro de la omnipotencia divina (Wierenga, 1989, pp. 15-17), el Doctor Angélico consideró que ni siquiera Dios puede hacer que esto se haga (Tomás de Aquino, 2002, p.19) porque la afirmación por la que se afirma existir se destruye a sí misma.

De tal modo que, distinguiendo entre razón y fe, si bien no es estrictamente herético atribuir a la divinidad tal capacidad, resulta necesario declararlo como algo racionalmente falso. Por tanto, haya o no incompatibilidad entre los conceptos de generación y eternidad no podrá tenerse por herética la tesis de que Dios puede crear algo que haya existido siempre. Pero si hay incompatibilidad entre los conceptos ello debería declarase falso. Mientras que, si no la hay, no sólo sería verdadero sino que constituiría un error hablar de otro modo.

Para poder comprender adecuadamente el reto al cual se enfrentaóTomás de Aquino es necesario tener en cuenta los capítulos finales del libro primero del Acerca del cielo en los cuales Aristóteles, en un intento de refutar todas las teorías rivales, define los conceptos básicos con los cuales debe entenderse la ingenerabilidad y eternidad del cosmos (Aristóteles, 2008b. I, 10-13).

Según el Estagirita, recibe el nombre de generable lo que no existiendo previamente llega luego a existir y no existe en un cierto momento y luego, en cambio existe. También se emplea este término si la generación de la cosa va de lo inexistente a lo existente, bien existiendo realmente la cosa, en virtud de su generación, bien no existiendo todavía, pero siendo capaz de ello. Ingenerable, en cambio, se dice de algo cuando existe actualmente no habiendo existido antes, sin generación ni cambio (Aristoteles, 2008b, I 11,280b6.). Igualmente se llama ingenerable a aquello que es absolutamente imposible que se genere de tal forma que en un cierto tiempo exista y que en otro no lo haga (Aristóteles, 2008b, I 11,280b10). Corruptible se dice de la cosa previamente existente que ya no existe o puede no existir tanto si se destruye y cambia alguna vez como si no. Lo mismo, por tanto, para lo incorruptible que no es otra cosa que lo que existe y que es imposible que se destruya de tal manera que, existiendo ahora, más adelante no exista o pueda no existir.(Aristóteles, 2008b, I 11,280b27.) De la combinación lógica de estas cuatro definiciones se deduce, según Aristóteles, la imposibilidad de afirmar al mismo tiempo que el universo sea generado y eterno debido a la absoluta incompatibilidad de ambos conceptos.

Llegados a este punto, es posible comprender con facilidad la agudeza del problema al que se enfrenta el Doctor Angélico. Para poder zafarse de la trampa aristotélica Tomás se vio necesariamente obligado a reformular otros dos principios básicos de la física aristotélica que le permitieron abrirse camino hacia una 
solución parcialmente filosófica, ya que parte de su argumentación se basará sobre principios de fe.

Necesariamente el dominico tuvo que apelar a una causa capaz de romper las restricciones físicas establecidas por el Filósofo y adentrarse en los problemas derivados de la consideración de la nada.

Así, según el Aquinate, la efectiva incompatibilidad de los conceptos, que obligaría a determinar falsa desde el punto de vista de la razón la posibilidad de que Dios haya creado algo que exista siempre, se puede producir por dos razones fundamentales que deben solventarse:

i. Si hay algo que haya existido siempre y que fuera creado por Dios, la causa agente de dicha generación debe preceder en duración a su efecto.

ii. Dicha generación ha de producirse de la nada, del no existir, pues así lo establece el dogma. ${ }^{21}$

\section{PRECEDENCIA DE LA CAUSA SOBRE EL EFECTO}

Tomás de Aquino se dispuso en primer lugar a demostrar que no es necesario que la causa agente - Dios- preceda en duración a su causado si así lo desea. Ello se debe a que en general no existe ninguna exigencia para que las causas que actúan instantáneamente precedan en duración a su efecto. Ciertamente, el propio Aristóteles también concedió la existencia de esta simultaneidad en algunos casos. El Estagirita distinguio entre causas actuales y causas potenciales (Aristóteles, 2008a, II 3, 195b15-20). Las primeras son simultáneas con sus efectos en su origen y cesación, mientras que las segundas no lo son, de tal forma que si la causa desaparece no lo hace el efecto o si éste de destruye la causa sigue existiendo (Marmodoro, 2007, pp.205-232).

El Aquinate empleó el ejemplo de la luz del sol que simultáneamente ilumina para reforzar su teoría de la creación simultánea. Sin embargo, pasando de un ejemplo físico a la compleja cuestión de la creación del mundo se corre el peligro de enlazar necesariamente la existencia del efecto con la de la causa primera y viceversa. Es decir, si bien al emplear la noción reformulada de creación, por la cual Dios no produce por el movimiento sino por medio de una emanación

\footnotetext{
21 "Quod autem non repugnent ad invicem, sic ostenditur. Si enim repugnant, hoc non est nisi propter alterum duorum, vel propter utrumque: aut quia oportet ut causa agens praecedat duratione; aut quia oport et quod non esse praecedat duratione ; propter hoc quod dicitur creatum a Deo ex nihilo fieri” (Tomás de Aquino, 2002, p. 20.)
} 
simultánea, se soluciona el problema de la precedencia de la causa agente, surgen sin embargo dos dificultades nuevas. En el caso ejemplar siempre que hay sol hay luz, pero ¿Siempre que hay Dios hay creación?

El primer problema que conlleva considerar a la divinidad una causa que actúa simultáneamente es el peligro convertirla al mismo tiempo en una causa que actúa necesariamente no pudiendo no causar.

En segundo lugar, se cae en la dificultad de sostener en términos aristotélicos que cesado el efecto, en este caso la creación a la que la fe atribuye un final, cese igualmente la existencia de Dios o que ésta sufra alguna alteración. Es decir, mientras el sol es sol ilumina. Si la iluminación cesa es porque su causa, el sol, o se ha destruido, o ha sufrido una alteración lo suficientemente importante como para perder su capacidad de iluminar o bien porque algo más poderoso le ha impedido realizar su efecto.

En los dos primeros casos, lo que antes era llamado sol, se torna algo distinto, puesto que la definición del sol y la de este nuevo ente son diferentes. En la cuestión que nos atañe, la cesación del efecto de la acción divina, aceptada por la escatología cristiana, podría también implicar bien la pérdida, el deterioro o la alteración de una cualidad divina o bien la existencia de una causa más poderosa que le impida seguir actuado.

Aunque Tomás de Aquino no reconoció explícitamente el problema en este punto, más adelante se encargó de rechazar tajantemente cualquier concepción de Dios como un agente que actúa obligado por la necesidad. La clave para desvincular a Dios del destino del mundo creado no es otra que reconocer en él una voluntad libre que, unida a su omnipotencia, le prive de los peligros impuestos por la argumentación del Estagirita y le diferencie radicalmente de la creación.

Frente a las causas reconocidas por el sistema aristotélico que obran ciega y necesariamente, Dios es la causa suprema que posee la capacidad de decidir y ordenar su propia conducta intencional. En última instancia, las condiciones de vinculación con lo creado dependen sencillamente del deseo, "si ipse voluisset" (Tomás de Aquino, 2002, p. 21), de la divinidad. De esta forma, el Aquinate sustituyó los posibles riesgos de la relación bidireccional de las causas actuales simultáneas aristotélicas por una determinación unidireccional de Dios hacia la creación. Así, el Ser supremo, creador de toda la sustancia de las cosas, puede hacer que lo causado por él exista siempre que él esté presente (Tomás de Aquino, 2002, p. 24), pero no viceversa y puede hacer también que ello se destruya sin sufrir degradación alguna.

Dado que Dios no pone nada de sí en la creación sino que es causa primera absolutamente trascendente al mundo, el destino final de su obra no afecta en 
absoluto a su esencia. Las criaturas, en cambio, que dependen de él absolutamente se hallan determinadas de modo necesario, configurando la imagen de un cosmos necesitado de tutela frente al universo plenamente autónomo de Aristóteles.

\section{LA CREACIÓN Y LA NADA}

El último problema que le queda por abordar a Tomás de Aquino es la controvertida cuestión de la creación a parir de la nada. Esta concepción constituye, en los textos de los físicos presocráticos, uno de los principales ejemplos de incompatibilidad conceptual.

El propio Aristóteles nos informa de que los que primero filosofaron, al indagar sobre la naturaleza, sostuvieron que nada puede generarse ni destruirse (Aristóteles, 2008a, I 8, 191a 25-35) puesto que lo generado tendría que llegar a ser o del ser o del no-ser. Sin embargo, ambas alternativas les resultaron imposibles ya que de lo que es no puede llegar a ser, puesto que ya es, y de lo que no es nada puede llegar a ser, puesto que tendría que haber algosubyacente.

Al igual que sus antecesores, Aristóteles, tomando esta cuestión en sentido absoluto, defendió que nada llega a ser de lo que no es ni de lo que es, pero sostuvo, apoyándose en su teoría de la pluralidad de los sentidos de ser, que existe un modo accidental de sostener esto con verdad (Aristóteles, 2008a, I 8, 191a5-15). El Estagirita solventó la cuestión señalando que las expresiones "llegar a ser de lo que es" y "llegar a ser de lo que no es" pueden ser entendidas en un sentido no absoluto.

Tomadas como "llegar a ser de lo que es en tanto que es" y "llegar a ser de lo que no es en tanto que no es" (Aristóteles, 2008a I 8, 191b12-27) puede explicarse cómo una cosa puede cambiar de un estado a otro y seguir siendo la misma cosa.

En todos los casos de llegar a ser tiene que haber siempre algo en lo que se llega a ser y algo de lo que se llega a ser (Aristóteles, 2008a, I 7,190a14.). Concretamente, según el Estagirita, lo que permanece es lo que no es un opuesto - la sustancia- que es sujeto siempre necesario de todo lo que llega a ser, pues sólo la sustancia no se predica de ningún otro sujeto, mientras que todo lo demás se predica de ella. Por tanto, en todos los diversos modos del llegar a ser — transfiguración, adición, sustracción, composición y alteración - las sustancias y entes simples llegan a ser de un sustrato subyacente informado (Aristóteles, 2008a, I 7,190b5-10). Así, dado que en todo cambio una parte permanece y otra se transforma todo lo que llega a ser proviene de su contrario o de algo intermedio y todo lo que se destruye lo hace en su contrario o en algo intermedio. No hay, por tanto, ni generación a partir de la nada ni destrucción absoluta en la nada. 
En el De aeternitate mundi el Aquinate comienza el análisis de esta cuestión apoyándose en lo dicho por Anselmo de Canterbury en el capítulo octavo del Monologion. Según el pensador inglés por la expresión "a partir de la nada" ha de entenderse que las criaturas han sido hechas pero que no había algo a partir de lo cual hayan sido hechas. Por tanto, fuera de la esencia suprema, todas las cosas que existen han sido hechas de la nada por Dios y no a parir de algo.

La interpretación correcta de esta expresión indica, según Tomás de Aquino, que con ello no se afirma un orden de lo que está hecho a la nada, como si fuera preciso que todo lo creado hubiera sido anteriormente nada y luego algo, sino que se sostiene que lo hecho no procede de nada anterior en el sentido de que no tuvo un sustrato subyacente (Tomás de Aquino, 2002, p. 27).

De esta forma, Tomás de Aquino abrió una nueva vía para intentar salvar el paso del no-ser al ser condenado por los griegos. La expresión ex nibilo puede ser interpretada, según el Doctor Angélico, de una segunda forma entendiendo con ello que la criatura ha sido hecha después de la nada. El término después indica claramente un orden. Sin embargo, el Aquinate llama la atención sobre el hecho de que el orden es múltiple y que debe ser entendido de diversos modos pudiendo distinguirse un orden de duración y un orden de naturaleza. Esta distinción previa le permite subrayar que de la afirmación de que la criatura existe después de la nada no se sigue que lo causado fuera anteriormente en el sentido de la duración nada y que después fuera algo, sino que debe entenderse que la nada es anterior por naturaleza al ente ${ }^{22}$.

El Aquinate establece a continuación que, desde el punto de vista del orden esencial, en cada cosa hay una prioridad de aquello que le conviene en sí misma frente a lo que la cosa tiene a partir de otro. Sin embargo, aceptada la creación de la totalidad de lo existente por Dios, se sigue que las criaturas no tienen su existencia por sí mismas sino por otro. De ahí que, consideradas en sí mismas, en el orden de naturaleza las criaturas no son nada, siendo por ello la nada anterior verdaderamente al ser. El mismo razonamiento es empleado por Tomás de Aquino para constatar que no se sigue de esto que aquello que existe siempre — lo eterno

\footnotetext{
22 "Praeterea, supponatur quod ordo ad nihil in praepositione importatus remaneat affirmatus, ut sit sensus: creatura facta est ex nihilo, idest facta est post nihil: haec dictio post ordinem importat absolute. Sed ordo multiplex est: scilicet durationis et naturae. Si igitur ex communi et universali non sequitur proprium et particulare, non esset necessarium ut propter hoc quod creatura dicitur esse post nihil, prius duratione fuerit nihil, et postea fuerit aliquid: sed sufficit, si prius natura sit nihilquam ens." (Tomás de Aquino, 2002, p. 26).
} 
y creado — sea simultáneamente nada y ente, como había advertido Aristóteles, porque no se postula ninguna precedencia cronológica.

En este sentido, la posición cristiana, interpretada por Tomás, no afirma que en algún momento la criatura haya sido nada, sino que la nada precede en el orden del existir a los entes. Todo lo que se hace, afirma el Aquinate, se hace a partir de lo no coincidente, es decir, de aquello que no coincide con aquello en lo que se va a convertir.

Por tanto, a la criatura se la ha hecho existente a partir de lo no-existente, o de la nada. Pero esto, no porque el ente haya sido en algún momento nada, sino porque sin aquello a lo que le debe su existir es nada. Con esto, de nuevo, Tomás intenta solventar el paso, prohibido por los griegos, del no-ser al ser, indicando que la creación divina no implica un cambio en la naturaleza de los entes. Es decir, lo que tiene lugar en la creación no es un proceso de generación tal y como ésta se efectúa en el mundo ya creado, donde las sustancias sufren alteraciones cuyas consecuencias son un cambio formal, sino una producción absoluta en la nada. No hay, por tanto, un momento en el que la naturaleza de las cosas coincida con la nada y otro en el que coincida con el ser, sino que sin materia y sin formas eternas, el ente es hecho existir.

\section{UNA VÍA PARA LA DEMOSTRACIÓN DE LA ETERNIDAD DEL MUNDO}

Establecido lo anterior, Tomás de Aquino reservó para el De aeternitate mundi una conclusión cuanto menos sorprendente. Tomando todas las objeciones aristotélicas que a lo largo del opúsculo intentó refutar, el Aquinate invierte la argumentación para convertirlas en apoyos defensivos del dogma de la creación, tarea para la cual se servirá de su hipótesis del ser creado y eterno.

En un giro inesperado, Tomás señala que si en la tesis de que Dios puede crear algo que nunca dejó de existir hubiera habido alguna repugnancia para el intelecto, esta no sólo habría reforzado la idea de la creación, sino que además habría sido una de las formas más eficaces para rechazar la eternidad del mundo. Dicho de otro modo, si ser hecho y ser eterno fuesen conceptos absolutamente incompatibles, bajo el respeto al dogma de que todo ente es fruto de la obra divina, el cristiano tendría que concluir que nada, salvo Dios, puede ser eterno.

Sin embargo, siendo éste el más sencillo de los caminos para el rechazo de toda posibilidad de hablar de eternidad, ninguno de los grandes teólogos lo ha considerado. La razón de esta ausencia en los discursos refutativos de los grandes pensadores cristianos no es otra, para Tomás, que el hecho de que efectivamente 
no existe tal incompatibilidad. A ojos del Doctor Angélico, el propio Agustín de Hipona parece haber subrayado esta correcta combinación lógica al señalar acerca de los platónicos:

Id quomodo intelligant invenerunt, non esse hoc scilicet temporis sed substitutionis initium. Sic enim, inquiunt, si pes ex aeternitate semper fuisset in pulvere, semper ei subesset vestigium, quod tamen vestigium a calcante factum nemo dubitaret; nec alterum altero prius esset,quamvis alterum ab altero altero factum esset. Sic, inquiunt, et mundus et dii in illo creati semper fuerunt, semper existente qui fecit; et tamen facti sunt. (Tomás de Aquino, 2002, p. 31)

Dios, como creador, es caracterizado metafóricamente por Agustín como el pie eterno y la creación como su huella en el polvo. Desde la eternidad estaría bajo la divinidad su huella de la que nadie duda que ha sido hecha por el que pisa. Creada porque fue hecha pero siempre existente porque uno no es anterior al otro (Tomás de Aquino, 2002, p.31).

Sin embargo, frente a la opinión de Agustín de Hipona, tan favorecedora para la tesis del Aquinate, parece que otros como el Damasceno y Hugo de San Víctor rechazaron tajantemente toda posibilidad de coeternidad señalando que "non aptum natum est quod ex non ente ad esse deducitur, coaeternum esse ei quod sine principio est et semper est" (Tomás de Aquino, 2002, p. 33) y que "ineffabilis omnipotentiae virtus non potuit aliud praeter se habere coaeternum, quo faciendo iuvaretur" (Tomás de Aquino, 2002, p. 33). No obstante, según Tomás de Aquino estas afirmaciones hallan su correcta interpretación en lo dicho por Boecio en el último libro del De consolatione:

Non recte quidam, cum audiunt visum Platoni mundum hunc nec habuisse initium temporis, nec habiturum esse defectum, hoc modo Conditori conditum mundum fieri coaeternum putant. Aliud enim est per interminabilem vital duci, quod mundo Plato tribuit, aliud interminabilis vital totam pariter complexam esse praesentiam, quod divinae mentis esse proprium manifestum est.(Tomás de Aquino, 2002, p. 34)

No hay que entender, por tanto, que con la hipótesis de un ser creado y eterno se afirme una efectiva coeternidad de la creación con Dios, sino que debe establecerse, con Boecio, una diferencia entre "ser conducido a lo largo de una vida interminable" y "abarcar la presencia eterna de una vida interminable". De nuevo, frente a la plena autarquía del cosmos aristotélico, el universo cristiano aparece como un conjunto de existencias que precisan de ser creadas, conducidas, tuteladas y mantenidas en el ser. 
Nada puede ser coeterno a Dios en la perspectiva tardomedieval, porque sólo la divinidad es inmutable, mientras que lo creado, a pesar de poder poseer una vida interminable, se desarrolla en la mutabilidad del tiempo.

Retomando, con ayuda del De civitate Dei, el ejemplo de los ángeles eternos y creados Tomás subraya que, aunque su inmortalidad no se desvanece con el tiempo, sin embargo sus movimientos con los que los tiempos se cumplen, se van desvaneciendo del pasado al futuro. La divinidad, en cambio, no corre el peligro, señalado por Aristóteles, de la actualización de potencias contradictorias porque en su movimiento no hay que decir que fue lo que ya no existe o que va a ser lo que todavía no es porque Dios es totalmente inmutable. En cambio, las criaturas somos simplemente "seres en el tiempo":

$(\ldots)<<$ ser en el tiempo $>>$ es ser afectado por el tiempo, y así se suele decir que el tiempo deteriora las cosas, que todo envejece por el tiempo, que el tiempo hace olvidar, pero no se dice que por el tiempo se llega a ser joven y bello; porque el tiempo es por sí mismo causa de destrucción, ya que es el número del movimiento, y el movimiento hace salir de sí a lo que existe. (Aristóteles, 2008a, IV 12, 221a30-221b4.)

Ana María C. Minecan

Universidad Complutense de Madrid - IRHS (CNRS) París

manecan@gmail.com

\section{BIBLIOGRAFÍA}

Agustín de Hipona (2005). La ciudad de Dios, Madrid: Biblioteca de Autores Cristianos. ARISTÓTELES (2008a). Física, Madrid: Gredos.

ARIstóteles, (2008b). Acerca del cielo, Meteorológicos, Madrid: Gredos.

BowIn, J. (2009). Aristotle on the Order and Direction of Time, Apeiron, 42 (1). pp. 49-78. Coope, U. (2005). Time for Aristotle: Physics IV.10-14, Oxford: Oxford Unvierstiy Press.

Coope, U. (2015). Self-motion as other-motion in Aristotle's Physics. In: Leunissen, M. (ed), Aristotle's Physics: A Critical Guide, Cambridge: Cambridge University Press. pp. 245-264.

CARROLL, W.E. (2013). A Universe, Created and Eternal: The Crisis of Faith and Reason in the Thirteenth Century. In Lavery, J., Groarke, L., Sweet, W., (Eds.) Ideas Under Fire Historical Studies of Pbilosopby and Science in Adversity, Madison: Fairleigh Dickinson University Press. pp. 89-108.

Denifle H., Chatelain, E. (1989) (Eds.) Chartularium Universitatis Parisiensis, Paris: Delalain. Grant, E. (1998). The Foundations of Modern Science in the Middle Ages; their Religious, Institutional and Intellectual contexts, Cambridge: Cambridge University Press.

IRÉNÉE DE LYON (1965). Contre les héresies, Paris: Sources chrétiennes. 
IRWIN, T. (2002). Aristotle's First Principles, Oxford: Claredon Press.

LANG, H. S. (1992). Aristotle's Physics and Its Medieval Varieties, Albany: State University of New York Press.

LANG, H. S. (2007). The Order of Nature in Aristotle's Physics: Place and the Elements, Cambridge: Cambridge University Press.

Lloyd, G. (2007). Aristóteles, Buenos Aires: Prometeo Libros.

Marmodoro, A. (2007). The Union of Cause and Effect in Aristotle: Physics III, 3. Oxford Studies in Ancient Philosophy 32.pp. 205-232.

OríGENES (2001). De principiis, Brill, Leiden, Boston.

Ruething, H. (1973). Die mittelalterilche Universität, Vandenhoeck, Goettingen.

Thijssen, J.M.M.H. (1997). What Really Happened on 7 March 1277? Bishop Tempier's

Condemnation and its Institutional context. In: Sylla, E., y McVaugh, M., (Eds.), Texts and contexts in ancient and medieval science: Studies on the Occasion of John E. Murdoch's Seventieth Birthday, Leiden: Brill.

TOMÁs DE AQUinO (2002). Sobre la eternidad del mundo, Madrid: Ediciones Encuentro.

Torrell, J-P. (2005). Saint Thomas Aquinas Voll: The Person and his work, Washington: The Catholic University of America Press.

Torrijos-Castrillejo, D. (2013). La causalidad del motor inmóvil. Hypnos 31, 2. pp. 234-266.

Van Steenberghen, F. (1972). La Filosofia nell XIII secolo. Milano: Ed. Vita e Pensiero.

Von Leyden, W. (1964). Time, Number and Eternity in Plato and Aristotle. Philosophical Quarterly 14 (54). pp. 35-52.

WeDIN, M. (2013). Aristotle on the Impossibility of Anaximander's Apeiron: On Generation and Corruption 332a20-25. Phronesis, 58, 2013. pp. 17-31

WierengA, E. R. (1989). The Nature of God: An Inquiry Into Divine Attributes, New York: Cornell University Press.

WippeL, J. (1981). Did Thomas Aquinas Defended the Possibility of an Enternally Created World? (The De aeternitate mundi Revisited). Journal of the History of Philosophy 29, no 1, January. pp. 21-37.

WissINK. J.B.M. (1990). The Eternity of the World in the Thougth of St. Thomas Aquinas and His Conteporares, Leiden: Brill. 